\title{
Effect of Cymbopogon citratus and Piliostigma reticulatum Aqueous Leaf Extracts on Rat Liver Function and In vitro Schizont Maturation Inhibition
}

\author{
${ }^{*}$ O. Oderinde, ${ }^{2} \mathrm{~A}$. Onu, ${ }^{3} \mathrm{~A}$. Shagari and ${ }^{4} \mathrm{O}$. Olaitan \\ ${ }^{1}$ Science Laboratory Technology Department, Umaru Ali Shinkafi Polytechnic Sokoto.College of Science and Technology,. \\ 2Department of Biochemistry, Usmanu Danfodiyo University, Sokoto. \\ ${ }^{3}$ Department of Biochemistry, Sokoto State University, Sokoto \\ ${ }^{4}$ Department of Pharmaceutical Science, Olabisi Onabanjo University, Ago-Iwoye, Ogun State \\ [ ${ }^{*}$ Corresponding Author: E-mail: Olalekanoderinde8@gmail.com; : : +2348137329299]
}

\section{ABSTRACT}

The most severe form of malaria is caused by the parasite Plasmodium falciparum, which undergoes antigenic variation. However, plant products continue to make an immense contribution to malaria chemotherapy. In this research, the inhibitory effect of $C$. citratus and $P$. reticulatum on schizont maturation was investigated using in vitro assay. Also, effect of the extract on some enzymatic and non-enzyme liver function parameters was determined after sub-chronic oral administration of the extracts to albino rats. From the result it was observed that $C$. citratus and $P$. reticulatum extract inhibited schizont growth with an $\mathrm{IC}_{50}$ of $7.25 \mathrm{mg} / \mathrm{L}$ and $3.25 \mathrm{mg} / \mathrm{L}$, respectively. The dosage $(250,750$ and $1500 \mathrm{mg} / \mathrm{kg})$ of both plants administered to experimental rats significantly $(p<0.05)$ increased the enzymatic parameters (AST, ALT and ALP) and non-enzymatic parameters (serum total proteins, albumin, total bilirubin and conjugated bilirubin) of liver function indices particularly at the high doses of 750 and $1500 \mathrm{mg} / \mathrm{kg}$ when compared with the control value. The finding of this research demonstrates that although $C$. citratus and $P$. reticulatum extract may have potential antimalarial activity but may have the potential to be hepatotoxic.

Keywords: Cymbopogon citratus, Piliostigma reticulatum, Plasmodium falciparum, Schizonts, Toxicity.

\section{INTRODUCTION}

The most lethal form of malaria is caused by $P$. falciparum transmitted to humans by female anopheles' mosquitoes during a blood meal (Kazhila, 2015). About 3.4 billion people are at risk of malaria infection in about 109 countries and territories (Diarra et al., 2015). It was estimated that 216 million malaria attacks occur worldwide and the number of malaria-related death was estimated at 600,000 (Danno et al., 2014). This protozoan parasite (Plasmodium falciparum) is characterized by long term persistent infection that can last for many months. The ability of this parasite to avoid clearance by the human immune system is dependent on its capacity to alter the surface exposed antigenic proteins that are vulnerable to antibody recognition and attack (Stuart and Artur, 2005; Ron and Kirk, 2009). The parasite only circulates in the blood for the first half of the erythrocytic growth cycle (Chris, 1999).
Malaria is a major obstacle to social-economic progress in sub-Saharan Africa, accounting for $40-60 \%$ of public health subventions (Tabuti, 2008; WHO, 2019). The disease causes premature deaths, may leave patients with permanent neurological damage and slashes productivity (Carrel et al., 2015). The serious problem of malaria is not only compounded by parasite resistance to synthetic drugs but also to increasing insecticidal resistance of mosquito vectors (Vamvaka et al., 2014). Plants and other natural products are starting points for future antimalarial therapies. Based on this, two plants Cymbopogon citratus and Piliostigma reticulatum were selected to investigate their inhibitory effect on schizont maturation of Plasmodium falciparum.

Cymbopogon citratus commonly known as lemon grass is a perennial tropical grass with thin long leaves and is one of the main medicinal and aromatic plants. It is cultivated mostly for its 
essential oil (EO) in tropical and subtropical regions of Asia, South America, and Africa (Nadjib et al., 2014). Nadjib et al. (2014) further reported that steam distillation produces EO plus hydrosols or aromatic waters which are often used against inflammatory diseases and microbial infectious. Also, biological research has shown that the various chemical compounds in EO possess antibacterial, antifungal, analgesic, and mosquito repellent properties (Nadjib et al., 2014). C. citratus is used in different parts of the world in the treatment of digestive disorders, fevers, menstrual disorder, rheumatism and other joint pains.

Previously, Puatanachokchai et al. 2002, stated that $C$. Citratus also known as lemon grass contains some components that may be used a cancer chemo preventive agents. In fact, the extract has been shown to inhibit rat colon carcinogenesis in animal models. The crop grows well in both tropical and subtropical climates at an elevation up to $900 \mathrm{~m}$. It can also be grown in semi-arid regions receiving low to moderate rainfall and grow well over medium fertile soils and moderate irrigation. A well-drained sandy loam is most suitable for the growth of the plant (Vanisha, 2012).

Piliostigma reticulatum (DC) Hochst (Ceasalpiniaceae) is a tree or shrub which is usually 1 to $10 \mathrm{~m}$ tall and occurs often in the form of bushes (Arbonnier, 2002). It is documented to be traditionally used in the treatment of many diseases such as dysentery, diarrhea, inflammation, neuralgia, smallpox,malaria, rheumatism. In addition, the leaves and bark of $P$. reticulatum are used in food for the preparation of local alimentary paste (Alexandre et al., 2010). The sedative and anticonvulsant properties of its leaves were also highlighted to have an estimated $L D_{50}$ greater than $5000 \mathrm{mg} / \mathrm{kg}$ of body weight. Also, the total ethanolic extract of stem bark of Piliostigma reticulatum reduced diarrhea at doses of 250, 500 and $1000 \mathrm{mg} / \mathrm{kg}$ body weight (Kazhila, 2015).

One of the major concerns in most drug discovery is the safety of the drug (Drug Safety, 2007).
Most secondary metabolites harnessed as lead compound in drug discovery are actually plant toxins for their protection so as to ward off parasites and rodents, while some are deposited as waste since the plants may not need them anymore (Drug Safety, 2007), hence the need to validate the safety of medicinal plants extracts. A major limitation to this study was the in ability to access the effects of these plant extracts on other organ functions such as the heart, kidney, muscle nor did we perform any other toxicological test, hence we advise that further extraction of the most active compound be isolated and a full toxicological analysis be performed.

\section{MATERIALS AND METHODS \\ Materials}

RPMI 1640 was purchased from GIBCO, gentamicin sulfate, sorbitol and geimsa stain was purchased from Sigma Aldrich, Germany, while aspartate aminotransferase, albumin, alanineaminotransferase, alkaline phosphate, protein and albumin kit were purchased from Randox, London.

\section{Sample Collection}

The plants, Cymbopogon citratus and Piliostigma reticulatum were collected at Farfaru area in Sokoto, Nigeria and were identified at the Taxonomy unit, Botany Department, Usmanu Danfodiyo University Sokoto, Nigeria. Samples were deposited in the herbarium of the same Department with voucher number (UDUS/283-332019) and (UDUS/284-33-2019).

\section{Malaria Parasite (Plasmodium falciparum)}

Ethical clearance for this research work was collected from the ethical clearance committee of Specialist Hospital Sokoto (SHS: 2019/00143/67). Malaria parasite was obtained from Usmanu Danfodiyo University Teaching Hospital, Sokoto, Nigeria. The blood was centrifuged at $3000 \mathrm{rpm}$ for 5 minutes. The plasma was collected and inactivated at $56{ }^{\circ} \mathrm{C}$ for 60 minutes. The cells were re-suspended in RPMI 1640 medium and then submitted for in vitro analysis 


\section{METHODOLOGY}

\section{Sample Preparation}

The leaves of the plants were air-dried under shade, pulverized in a wooden mortar using pestle to obtain a coarse material which was sieved and stored in plastic containers until used. Weighed amount of the plant material $(2 \mathrm{~kg})$ was soaked in cold distilled water for 24 hours after which it was filtered using sterile white Muslin cloth to remove debris. The solution was again filtered through a Whatman No.1 filter paper. The final filtrate was concentrated by freeze drying to obtain an $875 \mathrm{mg}$ of the aqueous extract and then the extract reconstituted in distilled water at $10 \%$ (W/N). The reconstituted extract was capped in plastic containers at $40{ }^{\circ} \mathrm{C}$ until required for testing of antimalarial activity.

\section{In-vitro Growth Inhibition of Plasmodium falciparum Schizonts by the Plant Extracts}

A continuous culture of $P$. falciparum malaria parasites was established using the method described by Trager and Jensen (1976). Erythrocytes was washed 3 times in RPMI 1640 to remove CPD, serum, and leukocytes if present, it was then diluted to $5 \%$ hematocrit with complete malaria culture media (cMCM) (RPMI 1640 supplemented with $37.5 \mathrm{mM}$ HEPES, $7 \mathrm{mM}$ D-glucose, $6 \mathrm{mM} \mathrm{NaOH}, 25 \mu \mathrm{g} / \mathrm{mL}$ gentamicin sulfate, $2 \mathrm{mM}$ L-glutamine and 10\% human serum) in small flasks of $25 \mathrm{~cm}^{3}(0.2 \mathrm{~mL}$ of packed cells to $4 \mathrm{~mL}$ of $\mathrm{CMCM}$ ). Parasites were then added to an appropriate parasitemia of 1.5 $\%$. The flask was kept in a candle jar with a loosened screw cap to produce low oxygen by the burnt out candle. The candle jar was then placed in an incubator at $37^{\circ} \mathrm{C}$. The MCM (Malaria culture medium) was replaced every day while the subculture was carried out two (2) times per week. It was ensured that parasitemia never exceed $15 \%$.

$$
\% \text { Inhibition }=\frac{\text { mean paracite count of control }- \text { mean paracite count of fraction }}{\text { mean paracite count of control }} \times 100
$$

Using a 96 well micro titer plate, each well was loaded with $100 \mu \mathrm{l}$ of warm sterile RPMI- 1640 medium, $50 \mu \mathrm{l}$ infected red blood cells (iRBC) with a parasitaemia of $2 \%$, a hematocrit of $2 \%$ and $20 \mu \mathrm{l}$ sterilized serum were incubated with 20 $\mu \mathrm{l}$ of the plant extracts over a concentration range of 0.15 to $10 \mathrm{mg} / \mathrm{L}$ for 48 hours. The negative control was prepared by addition of only the solvent in place of the extract. Parasitaemia was evaluated by Giemsa-stained smears. Precisely $50 \mu \mathrm{l}$ of the malaria infected blood sample previously synchronized with $25 \mu \mathrm{g} / \mathrm{mL}$ of sorbitol to maintain a synchronous schizont stage (Ranford-Cartwright et al., 2010) was used to make thick and thin film smear on pre-labeled slides in accordance with the method described by Chukwuocha, (2016). The slides were examined under $\times 100$ oil immersion objective. Thin smears were used for identification of the malaria parasites growth stage. Slides with gametocytes other than Plasmodium falciparum schizont were discarded. Thick smears were used for the parasites count. The number of asexual forms mostly young trophozoites which appeared as incomplete rings or spot of blue cytoplasm with a detached red chromatin dot was counted against 100 leucocytes and then multiplied by 8000 (standard leucocytes count per $\mathrm{mm}^{3}$ of blood) for blood with low parasitemia, while, slides with high density parasite only 10 fields were examined.

The percent inhibition of parasite growth was calculated relative to the untreated control group (considered $100 \%$ growth) for $n=5$ wells per dose. Meanwhile, the concentration causing 50\% inhibition $\left(\mathrm{IC}_{50}\right)$ was obtained by extrapolating the $50 \%$ position on the $\mathrm{Y}$-axis against the concentration on the $X$-axis from the extract concentration response curve. 


\section{Sub-chronic Toxicity of Cymbopogon citratus and Piliostigma reticulatum}

Sub-chronic toxicity was conducted for Cymbopogon citratus and Piliostigma reticulatum according to the OECD 407 guideline. For the aqueous extract of each of the plant, twenty (20) rats were divided into four groups comprising three tests' groups and one control group. Each group consisted of five rats. Three doses were selected; 250, 750 and $1500 \mathrm{mg} / \mathrm{kg}$ body weight and were administered orally to groups 2, 3 and 4 , respectively. Group 1 (Control group) received only distilled water as treatment. The animals were individually marked and dosed accordingly. On the 29th day, after an overnight fast, the rats were anaesthetized in chloroform vapour and blood samples were collected from the animals by cardiac puncture into labeled vacutainers for biochemical assays.

\section{Biochemical Analysis}

The methodologies for the biochemical analysis to determine the effect of both plants on the liver function after oral administration of both plants were adapted from Onu et al. (2013). Accordingly, Serum total protein was determined using the biuret method; cupric ions in the biuret reagent react with the peptide bonds of the protein molecule in an alkaline solution to form a blue colored complex (Doumas, 1992). Albumin was determined using the Bromocresol Green method; albumin binds with Bromocresol Green in an acidic medium to form a blue-green complex whose colour is proportional to the concentration of albumin in the serum (Spencer and Price, 1977).

$\begin{array}{ll}\text { Transaminase } & \text { activity } \\ \text { aminotransferase } & \text { (AST) aspartate } \\ \text { alanine, }\end{array}$ aminotransferase (ALT) was determined using the Reitman and Frankel (1957) method; ALT was measured by monitoring the concentration of pyruvate dehydrazone that is formed with 2,4dinitrophenylhydrazine while AST was measured by monitoring the concentration of oxaloacetate hydrazone that is formed with 2,4dinitrophenylhydrazine. Alkaline phosphatase (ALP) activity was determined using the colorimetric method of Rec (Deutsche, 1972); the hydrolysis of 4-nitrophenyl phosphate at alkaline $\mathrm{pH}$ to4-nitrophenol and inorganic phosphate is catalyzed by alkaline phosphatase and the intensity of the colour is directly proportional to the activity of ALP.

The method of Yuji and Yoshikatsu, (1994) was used to determine total and conjugated bilirubin. Bilirubin reacts with diazotized sulphanilic acid to form azobilirubin. Caffeine is an accelerator and gives a rapid and complete conversion to azobilirubin. The pink acid azobilirubin is converted to blue azobilirubin by an alkaline tartrate reagent and the absorbance of the bluegreen solution was read spectrophotometrically at $540-600 \mathrm{~nm}$.

\section{Data Analysis}

Values obtained for the liver function test and the in vitro study are presented as Mean \pm Standard Deviation. Data were subjected to statistical analysis using Instat software version 8. Means were compared using student $t$-test and the level of significance was determined at $p<0.05$.

\section{RESULTS}

The result of in-vitro percent growth inhibition of $P$. falciparum schizont by Cymbopogon citratus and Piliostigma reticulatum aqueous leaf extracts is presented in Table 1. From the result it shows that effect of $C$. citratus and $P$. reticulatum were dose-dependent. A concentration of $10 \mathrm{mg} / \mathrm{ml}$ of C. citratus had the highest activity of $96 \pm 1.29 \%$ inhibition while $P$. reticulatum $10 \mathrm{mg} / \mathrm{ml}$ had $86 \pm$ $2.33 \%$ inhibition. The lower doses $(2.5$ and 0.5 $\mathrm{mg} / \mathrm{L}$ ) of $C$. citratus where both above the $50 \%$ inhibition. While $P$. reticulatum extract only the dose of $2.5 \mathrm{mg} / \mathrm{ml}$ and above were above $50 \%$ inhibition.

Meanwhile Table 2 shows the effect of oral administration of Cymbopogon citratus aqueous leave extract on liver function parameters of rats. From the result there was no significant difference $(p>0.05)$ in AST, ALT, albumin and total protein in all the dose groups compared to the control group. The 750 and $1500 \mathrm{mg} / \mathrm{kg}$ dose 


\section{Nigerian Journal of Basic and Applied Science (December, 2021), 29(2): 01-08}

groups significantly reduced $(p<0.05)$ alkaline phosphatase (ALP) in a dose-dependent manner when compared to the control group. A significant increase $(p<0.05)$ was observed in both total and conjugated bilirubin as shown on Table 2 .

Table 1: In-vitro Growth inhibition of $P$. falciparum Schizont by Cymbopogon citratus and Piliostigma reticulatum aqueous leaf extracts

\begin{tabular}{cccc}
\hline S/N & CONCENTRATION (mg/L) & \multicolumn{2}{c}{ PERCENT INHIBITION } \\
\hline & & C. citratus & P. reticulatum \\
1 & 10 & $96 \pm 1.29^{\mathrm{a}}$ & $86 \pm 2.33^{\mathrm{b}}$ \\
2 & 5 & $92 \pm 1.01^{\mathrm{a}}$ & $78 \pm 1.62^{\mathrm{b}}$ \\
3 & 2.5 & $80 \pm 0.00^{\mathrm{a}}$ & $78 \pm 4.65^{\mathrm{b}}$ \\
4 & 0.50 & $71 \pm 3.25^{\mathrm{a}}$ & $20 \pm 3.36^{\mathrm{b}}$ \\
5 & 0.15 & $30 \pm 6.23^{\mathrm{b}}$ & $16 \pm 2.00^{\mathrm{b}}$ \\
\hline
\end{tabular}

Values are expressed as Mean $\pm S D, n=5$. Data with different alphabetic superscript on the same row are significantly $(P<0.05)$ different

Effect of oral administration of Piliostigma reticulatum aqueous leaves extract on liver function parameters of rats is presented on Table 3. From the table it is observed that ALT, AST, total and conjugated bilirubin levels in the 1500 $\mathrm{mg} / \mathrm{kg}$ group were significantly increased when compared to the control group. ALP, total protein and albumin levels in the treatment groups were not significantly different $(p>0.05)$ when compared to the control groups.

Table 2: Effect of oral administration of Cymbopogon citratus aqueous leaves extract on liver function parameters of rats

\begin{tabular}{lcccc}
\hline PARAMETERS & CONTROL & $\mathbf{2 5 0} \mathbf{~ g ~} / \mathbf{k g}$ & $\mathbf{7 5 0} \mathbf{~ m g} / \mathbf{k g}$ & $\mathbf{1 5 0 0 ~} \mathbf{~ g} / \mathbf{k g}$ \\
\hline AST (U/l) & $187.80 \pm 28.9$ & $185.73 \pm 14.18$ & $155.08 \pm 2.04$ & $205.10 \pm 3.07$ \\
ALT (U/l) & $139.33 \pm 64.10$ & $166.38 \pm 69.71$ & $142.48 \pm 4.51$ & $113.77 \pm 7.67$ \\
ALP (U/l) & $413.43 \pm 24.97$ & $417.23 \pm 39.11$ & $303.50 \pm 34.11^{*}$ & $294.67 \pm 46.10^{*}$ \\
TOTAL PROT. (g/dL) & $6.53 \pm 0.28$ & $6.83 \pm 0.21$ & $7.47 \pm 0.21$ & $7.15 \pm 0.09$ \\
ALBUMIN (g/dL) & $2.33 \pm 0.05$ & $2.43 \pm 0.06$ & $2.32 \pm 0.04$ & $2.35 \pm 0.02$ \\
TOTAL BIL. (mg/dL) & $0.83 \pm 0.08$ & $1.29 \pm 0.16^{*}$ & $1.52 \pm 0.00^{*}$ & $1.14 \pm 0.03^{*}$ \\
CONJ.BIL. (mg/dL) & $0.17 \pm 0.05$ & $0.21 \pm 0.03$ & $0.10 \pm 0.03$ & $0.35 \pm 0.12^{*}$ \\
\hline
\end{tabular}

Values are expressed as mean $\pm S D, n=5$. Data with * are Significantly $(P<0.05)$ different from control. AST (Aspartate Amino Transferase), ALT (Alanine Amino Transferase), ALP (Alkaline Phosphatase), Total Prot (Total Protein), Total Bil (Total Bilirubin), Conj. Bil (Conjugated Bilirubin)

Table 3: Effect of oral administration of Piliostigma reticulatum aqueous leaves extract on liver function parameters of rats.

\begin{tabular}{lllll}
\hline PARAMETERS & CONTROL & $\mathbf{2 5 0} \mathbf{~} \mathbf{g} / \mathbf{k g}$ & $\mathbf{7 5 0} \mathbf{~ g ~} / \mathbf{k g}$ & $\mathbf{1 5 0 0 ~} \mathbf{~ g} / \mathbf{k g}$ \\
\hline AST (U/I) & $122.48 \pm 40.88$ & $164.95 \pm 13.74$ & $189.03 \pm 1.09^{*}$ & $178.85 \pm 9.09^{*}$ \\
ALT (U/l) & $31.18 \pm 10.98$ & $115.13 \pm 4.47^{*}$ & $78.33 \pm 1.84^{*}$ & $96.83 \pm 0.72^{*}$ \\
ALP (U/I) & $246.90 \pm 109.64$ & $496.88 \pm 110.67$ & $353.15 \pm 58.18$ & $226.00 \pm 74.39$ \\
TOTAL PROT. (g/dL) & $5.03 \pm 1.69$ & $6.68 \pm 0.10$ & $6.80 \pm 0.05$ & $7.18 \pm 0.30$ \\
ALBUMIN (g/dL) & $1.63 \pm 0.54$ & $2.25 \pm 0.05$ & $2.18 \pm 0.05$ & $2.33 \pm 0.048$ \\
TOTAL BIL. (mg/dL) & $0.76 \pm 0.26$ & $1.36 \pm 0.04$ & $1.50 \pm 0.02^{*}$ & $1.60 \pm 0.05^{*}$ \\
CONJ. BIL. (mg/dL) & $0.11 \pm 0.03$ & $0.13 \pm 0.03$ & $0.14 \pm 0.05$ & $0.23 \pm 0.01^{*}$ \\
\hline
\end{tabular}

Values are expressed as mean $\pm S D, n=4$. Data with ${ }^{*}$ are Significant $(P<0.05)$ different from control.

AST (Aspartate Amino Transferase), ALT (Alanine Amino Transferase), ALP (Alkaline Phosphatase), Total Prot (Total Protein), Total Bil (Total Bilirubin), Conj. Bil (Conjugated Bilirubin) 


\section{DISCUSSION}

The challenge of any drug discovery effort is to identify and characterize medicinal plant extract properties that are predictive of good efficacy and safety in humans (Reichel and Lienau, 2015). The traditional use of plants for the treatment of human malaria and fevers all over the world has been widely documented (Mohomoodally, 2013; Adebayo and Kretti, 2011) and the number of investigations into their effects both in vitro and in vivo is increasing (Guantai and Chibale, 2011; Ginsburg and Deharo 2011; Schmidt et al., 2012). However, little is known about their efficacy and safety (Zofou et al., 2011). The validation of plants that are used for traditional treatments for malaria is currently stimulating the interest of researchers across the world (Newman and Cragg, 2012). Accordingly, this research was able to show that the tested plants have schizont growth inhibition and therefore may affirm the claims that $C$. citratus and $P$. reticulatum have antimalarial activity owing to the presence of phyto-compounds and its wide use in traditional treatments for malaria (Chukwuocha et al., 2016). It was also observed that although $C$. citratus had significant $(p<0.05)$ higher activity than $P$. reticulatum at all doses, $P$. reticulatum; however, had a lower $\mathrm{IC}_{50}(3.25 \mathrm{mg} / \mathrm{l})$ than $C$. citratus which had an $\mathrm{IC}_{50}$ of $7.25 \mathrm{mg} / \mathrm{l}$. A likely explanation for this observation may be the difference in the qualitative and quantitative compositions of phyto-compounds in different plants (Roberto et al., 2013). It is not uncommon for plants to have therapeutic properties due to the presence of several phytochemicals (Rabiu et al, 2018) which includes alkaloids, glycosides, terpenes, saponins, flavonoids, essential oils. Water being a universal solvent is able to isolate a wide range of analyte and one more of this analyte may be responsible for the observed inhibitory activity (Muhammed et al., 2012).

From the results in Tables 2 and 3 , all parameters analyzed are indicative of possibility of being safe only at low doses since they were not significantly different when compared with the control group.
However, the high doses administered may not be safe when administered for a long period of twenty-eight days (28), because they may impair liver function.

\section{Conclusion and Recommendation}

The result of the study showed that $P$. reticulatum and $C$. citratus was able to inhibit schizont growth in vitro and may have potential to replicate this activity in vivo. Also P. reticulatum and C. citratus administration at lower doses did not alter liver function but the higher doses of both plants should be administered with caution.

\section{REFERENCES}

Adebayo, J., \& Kretthli, A.U. (2010). Potential Antimalarials from Nigerian Plants: A review, isolation of novel antimalarial compounds/biomolecules from medicinal plants. Journal of Ethnopharmacology, 133(2): 289-302.

Alexandre, Z., Jean K., Noufou, O., Rasmata, O., \& Innocent P. G. (2010) Antioxidant and antibacterial activities of Piliostigmareticulatum(DC.)

Hochstextracts. African Journal of Biotechnology, 9(33): 5407-5411.

Arbonnier, M (2002), Tres Shrubs and Lianes of west African dry zones. CIRAD Margraf Publ. GmBH. Scientific Research Traditional medicines in Africa: An Appraisal of ten Potent African Medicine plants. M Fanzi Mahomoodally African Traditional Medicines Volume 2013/Article 1D 617459.

Carrel, M., Patel, J., Taylor, S.M., Janko M., Mwandagalirwa M. K., Tshefu A. K., \& Emch M. (2015). The geography of malaria genetics in the democractic republic of Congo. A complex and fragmented landscape. Societal Science Medicine, 3: 103 -107.

Chris, I. N. (1999) Antigenic variation in Plasmodium falcifarum: Mechanism and consequences. Current Opinion in Microbiology, 2: 420 -425 


\section{Nigerian Journal of Basic and Applied Science (December, 2021), 29(2): 01-08}

Chukwuocha, U.M., Fernández-Rivera, O., Legorreta-Herrera, M. (2016) Exploring the antimalarial potential of whole Cymbopogoncitratus plant therapy. Journal of Ethnopharmacology, 4(193):517-523.

Danno K., Rerolle F., de Sigalony S., Colas, A., Terzan, L., \& Bordet, M. (2014). China rubra for side effects of quinine: a prospective randomized study in pregnant women with malaria in cotonou, Benin. Homeopathy, 103(3) 165-171.

Deutsche, G. K. C. (1972). "Optimised standard colorimetric methods. (Serum Alkaline Phosphatase)," Journal of Clinical Chemistry \& Clinical Biochemistry, 10:182.

Diarra, N., VantKlooster, C., Togola, A., Diallo D., \& Willcox M. (2015) Ethnobotanical study of plants used against malaria in Selingue subdistrict. Mali Journal of Ethnopharmacology, 166: (2) 352-360.

Doumas, B. T. (1992). Plants and Their Pharmacological Properties: A Review. Journal of Anesthesiology. Vol. 6, No. 1, 2018, pp. 15-25.

Drug Safety, (2007). Nature reviews Drug discovery 6, 937 Medical Laboratory Manual for Tropical Countries, Quoted in Cheesbrough M., (1992) ELBS, Cambridge, UK, 2nd edition.

Ginsburg, H., \& Deharo, E. (2011) A call for using natural compounds in the development of new antimalarial treatments-an introduction. Malarial Journal, 10(Suppl 1): S1.

Guantai, E., \& Chibale, K. (2011). How can natural products serve as a viable source of lead compounds for the development of new/novel anti-malarials? Malar Journal, 10(Suppl 1):S2.

Kazhila, C. C. (2015) Plants as antimalarial agents in sub- Saharan Africa. Actal Tropical, 152:32-48.

Mohomoodally, F. (2013). Traditional medicine in Africa: An appraisal of ten potent African Medicinal Plants. Evidence-Based complementary and alternative medicine. 2013: Article ID 617459.

Muhammed, M., Aboki, M.A., Saidu, H.M., Victor, O., Tawakalitu, A., \& Maikano, S. A. (2012). Phytochemical and some Antimicrobial Activity of cassia Occidentalis. International Journal of Science and Technology, 2(4): 561-568.

Nadjib, B. M., Amine, F. M., Abdelkrim, K., Fairouz, S. and Maamar, M. (2014). Liquid and Vapour Phase Antibacterial Activity of Eucalyptus Globules Essential Oil = Susceptibility of Selected Respiratory Tract Pathogen, American Journal of Infections Disease, 10(3):105117

Newman, D.J., \& Cragg, G.M. (2012) Natural products as sources of new drugs over the 30 years from 1981 to 2010. Journal of Natural Production, 75:311-335.

Onu, A., Saidu, Y Ladan, M. J., Bilbis, L. S., Aliero, A. A., \& Sahabi, S. M. (2013) "Effect of Aqueous Stem Bark Extract of Khaya senegalensis on Some Biochemical, Haematological, and Histopathological Parameters of Rats," Journal of Toxicology, Article ID 803835.

Puatanachokchai, R., Kishida, H., Denda, A., Murata, N., Komishi, Y., Vinitketkumnuen, $U$. and Nakae, D. (2002). Inhibitory effects of lemon grass (Cymbopogon Utratus, stapf) extract on the early phase of hepatocar cinogenesis after initiation with cliethy initrosamine in male fischer 344 rats. Cancer letters, 183 (I): 9-15.

Rabiu M. K., Abdulkadir, S., Sani A. K., Gambo C. (2018). Phytochemical Compositions in Some Nigerian Medicinal Plants and their Pharmacological Properties International Journal of Anesthesia and Clinical Medicine, 6: 15-25.

Ranford-Cartwright, L.C., Sinha, A., Humphreys, G.S., \& Mwangi, J. M. (2010). New synchronization method for Plasmodium falciparum. Malarial Journal, 9: 170. 
Oderinde et al: Effect of Cymbopogon citratus and Piliostigma reticulatum Aqueous Leaf Extracts....

Reichel, A and Lienau, P (2015). Pharmacolokinetics in Drug discovery: An Exposure Centred Approach to optimizing and predicting Drug efficacy and safety. Handbook of experimental Pharmacology. Dol 10.1007/164-201526.

Reitman, S., \&Frankel, S. (1957) "A colorimetric method for the determination of serum glutamic oxalacetic and glutamic pyruvic transaminases," American Journal of Clinical Pathology, 28:56-63.

Roberto, L., Valentina, P., Carmela, A. M., Gabriele, C., Fabrizio, L., Valentino, F., \& Luigi, F. D. (2013) Variations in the Phytochemical Contents and Antioxidant Capacity of Organically and Conventionally Grown Italian Cauliflower (Brassica oleracea L. subsp. botrytis): Results from a Three-Year Field Study. Journal of Agricultural and Food Chemistry, 61(43):

Ron D., Kirk W. Deitsch, D. (2009): Genetics and Antigenic variation in plasmodium falcifarum. Current Genetics, 55: 103110.

Schmidt, T.J., Khalid, S. A., Romanha, A. J., Alves, T.M.A., Biavatti, M.W., Brun, R., Costa, F.B., Castro, S.L., Ferreira, V.F., Lacerda, M.V.G., Lago, J.H.G., Leon, L.L., Lopes, N., Amorim, R.C.N, Niehues, M., Ogungbe, I.V., Pohlit, A.M., Scotti, M.T., Setzer, W.N., Soeiro, M.N.C., Steindel. M., \& Tempone, M.G. (2012) The potential of secondary metabolites from plants as drugs or leads against protozoan neglected diseases - part I. Current Medicine Chemistry, 19:21282175.

Spencer, K., \& Price, C. P. (1977) "Guidelines on standard operating procedures for clinical chemistry," Annals of Clinical Biochemistry, 14:105-115.

Stuart, A., Ralph, D. and Artur, S. (2005): The epigenetic control of antigenic variation in plasmodium falcifarum. Current Opinion in microbiology, 8: 434-440.

Tabuti, J. R. (2008). Herbal medicines used in the treatment of malaria in Budiope county, Uganda. Journal of Ethnopharmacology, 116(1): 33-42.

Trager, W., \& Jensen, J. B. (1976). Human malaria parasites in continuous culture. Science, 193:673-675.

Vamvaka E., Twyman, R. M., Christou P., \& Capell T. (2014). Can plant biotechnology help break the HIV-Malaria link? Biotechnology Advances, 32(3): 575-582.

Vanisha S., Nambiar, H. and Hema, M. (2012): Potential Functions of Lemon Grass (Cymbopogoncitratus) in Health and Disease. International Journal of Pharmaceutical \& Biological Archives, 3(5):1035-1043

Yuji, S., \& Yoshikatsu, S. (1994) Determination of Serum Bilirubin by the Diazo Method Using the Diazotized 3-Nitroaniline ReactingReadily with the Photoproducts of Bilirubin. Jpn Journal of Clinical Chemistry. 23: 158-163,

WHO. (2019). World malaria report Geneva: World Health Organization; 2018. https://apps.who.int/iris/bitstream/handle 110665/275867/9789241565653eng.pdf?ua $=1$.

Zofou, D., Kowa, T.K., Wabo, H.K., Ngemenya, M.N., Tane, P., \& Titanji, V. P. (2011) Hypericumlanceolatum (Hypericaceae) as a potential source of new antimalarial agents: a bioassay-guided fractionation of the stem bark. Malarial Journal, 10:167. 